\title{
In vitro binding and survival assays of Leishmania parasites to peripherical blood monocytes and monocyte-derived macrophages isolated from dogs naturally and experimentally infected with Leishmania (Leishmania) chagasi
}

\author{
Weverton M Sampaio ${ }^{1}$, Eliane P Moura², Felipe CS Arruda1, Raul R Ribeiro², \\ Cíntia F Alves ${ }^{2}$, Ferdinan A Melo ${ }^{1}$, Ana Paula SM Fernandes ${ }^{3}$, \\ Marilene SM Michalick ${ }^{2}$, Maria N Melo ${ }^{2}$, Washington L Tafuri ${ }^{1}$ and \\ Wagner L Tafuri*4
}

Address: ${ }^{1}$ Departamento de Anatomia Patológica, Faculdade de Medicina, Universidade Federal de Minas Gerais, Belo Horizonte, MG, Av Alfredo Balena 190, CEP 30130-100, Brazil, '2Departamento de Parasitologia, Instituto de Ciências Biológicas, Universidade Federal de Minas Gerais, Belo Horizonte, MG, Av Antonio Carlos 6627, CEP31270-901, Brazil, 3Departamento de Análises Clínicas e Toxicológicas, Faculdade de Farmácia, Universidade Federal de Minas Gerais, Belo Horizonte, MG, Av Antonio Carlos 6627, CEP31270-901, Brazil and ${ }^{4}$ Departamento de Patologia Geral, Instituto de Ciências Biológicas, Universidade Federal de Minas Gerais, Belo Horizonte, MG, Av Antonio Carlos 6627, CEP31270-901, Brazil

Email: Weverton M Sampaio - godsamp2003@yahoo.com.br; Eliane P Moura - elianeperlatto@brfree.com.br;

Felipe CS Arruda - felipe_arruda@hotmail.com; Raul R Ribeiro - rrvet@yahoo.com.br; Cíntia F Alves - cintiafontes@oi.com.br;

Ferdinan A Melo - ferdinanmelo@yahoo.com.br; Ana Paula SM Fernandes - anav@net.em.com.br;

Marilene SM Michalick - michalik@icb.ufmg.br; Maria N Melo - melo@icb.ufmg.br; Washington L Tafuri - wltafuri@yahoo.com.br;

Wagner L Tafuri* - wagner@icb.ufmg.br

* Corresponding author

\section{Published: 30 May 2007}

BMC Veterinary Research 2007, 3:II doi:10.1 186/1746-6148-3-1।

This article is available from: http://www.biomedcentral.com/I746-6/48/3/II

(C) 2007 Sampaio et al; licensee BioMed Central Ltd.

This is an Open Access article distributed under the terms of the Creative Commons Attribution License (http://creativecommons.org/licenses/by/2.0), which permits unrestricted use, distribution, and reproduction in any medium, provided the original work is properly cited.

\begin{abstract}
Background: There are a few works considering the characterization of canine monocyte-derived macrophages as well as a standardized procedure for isolation, culture, and infection of these cells with Leishmania. We have performed several modifications in order to improve the canine monocyte-derived macrophage cultures. In addition, we have done a comparative study between monocytes and monocyte-derived macrophages from dogs naturally and experimentally infected with $L$. chagasi.

Results: In the presence of exogenous serum, opsonized Leishmania promastigotes binds better to monocytes/macrophages than without serum. Otherwise, this binding occurs due to the strict correlation between the opsonized biologic particles with the third receptor of the complement (CR3-CDIIb/CDI8). In fact, our assays with CDI Ib confirmed the importance of this receptor for canine cells and the $L$. chagasi experimental system. Moreover, monocytes obtained from naturally infected dogs have shown a higher number of monocytes bounded to promastigotes. The experimental results regarding survival have shown that promastigote forms of opsonized $L$. chagasi were more infective, because we found higher numbers of promastigotes bound to the different cells. As a consequence, after forty-eight hours of binding, higher numbers of amastigotes appeared inside monocyte-macrophages.

Conclusion: These studies have given support to continue comparative studies involving canine monocytes, monocyte-derived macrophages and peritoneal macrophages. Since we have standardized the canine cell culture, we are looking forward to determining the phenotypic properties of these cells before and after L. chagasi infection using flow cytometry.
\end{abstract}




\section{Background}

Canine visceral leishmaniasis (CVL) is caused by Leishmania infantum (syn. L. chagasi in America) [1]. This protozoan is transmitted by the bite of the female phlebotomine sand fly of the species Lutzomyia longipalpis (in America) [2]. Protozoa of the genus Leishmania are dimorphic obligate intracellular parasites that reside within mononuclear phagocytes in the mammalian host. In America, dogs infected with L. chagasi constitute the main domestic reservoir of the parasite and play an important role in transmission to humans, in which the parasite causes the visceral disease, characterizing it as a zoonosis.

The immune response against Leishmania is highly dependent upon macrophages. Although these are the host cells targeted for infection, they are competent to present antigen and kill intracellular Leishmania [3]. Isolation, culture and characterization of alveolar and peritoneal macrophages [4], bone marrow-derived macrophages [5], and canine macrophage cell lines derived from malignant histiocytosis [6] have been described. Also, the interaction of Leishmania promastigotes with mononuclear phagocytes has been characterized, and multiple receptor-ligand interactions have been implicated in the attachment to, and uptake of, promastigotes by macrophages [7]. These interactions include the binding of parasite surface molecules (lipophosphoglycan and gp63) or host-derived opsonins (complement, fibronectin and immunoglobulin) to multiple macrophage receptors.

Many in vitro methods for investigating the Leishmaniamacrophage interaction have been described in the literature. These techniques involve quantifying parasites and macrophages on coverslips, where parasites can be counted by conventional microscopy, immunofluorescent microscopy (immunolabelled parasites) or radioactivity associated with the cell lysates [8-10]. However, these techniques are laborious and time-consuming and do not allow the cells and surface receptors involved in parasite uptake to be characterized accurately. Moreover, most of these studies have involved human or murine monocytes/macrophages and Leishmania major. Few in vitro studies using canine macrophages and Leishmania chagasi have been published. As far as we know, Madeira et al. (1999) [11] were the first to assay binding between different species of Leishmania and canine macrophages. Recently, Gonçalves et al. (2005) [12] developed a novel method using flow cytometry and canine peritoneal macrophages to study this interaction, and Bueno et al. (2005) [13] described a phenotypic, functional and quantitative characterization of canine peripheral blood monocytederived macrophages. The cells in these studies were inoc- ulated with L. chagasi promastigotes to assess their phagocytic activity.

There have been few studies characterizing canine monocyte-derived macrophages and employing a standardized procedure for isolation, culture and infection of these cells with Leishmania. To date, as described by Ho \& Babiuk (1979) [14] and Bueno et al. (2005) [13] (personal communication), our own experience has shown that the number of monocytes that can be isolated from dog blood is usually low, especially for obtaining monocytederived macrophage cultures. In this study, therefore, we have introduced several modifications to improve canine monocyte-derived macrophage cultures. We have also compared monocytes and monocyte-derived macrophages from dogs naturally and experimentally infected with L. chagasi.

\section{Results}

The binding of $\mathrm{L}$. chagasi promastigotes to monocytes as determined by optical microscopy

By microscopy, we easily observed the adhesion of Leishmania promastigotes to monocytes in the presence of C5D serum (Figure 1(a). This result was statistically significant $(\mathrm{p}<0.01)$ and occurred in both groups of infected animals, as depicted in Figure 2(a), 2(b). The adhesion was independent of the concentration of promastigotes.

Interestingly, significantly more monocytes from naturally-infected animals than from experimentally-infected ones were bound to Leishmania promastigotes ( $\mathrm{p}<0.01$ ) (Figure 3). This was also independent of the promastigote concentration and of the presence or absence of C5D serum. However, in the presence of C5D serum, the average number of Leishmania promastigotes bound to monocytes (100 cells/well) was 1.67 for naturally-infected and 0.32 for experimentally-infected dogs. In the absence of serum, these averages decreased to 0.55 and 0.05 , respectively.

The binding of L. chagasi promastigotes to monocytes as shown by flow cytometry

Aliquots of CFSE-stained promastigotes were evaluated using the flow cytometer to analyze the efficiency of CFSE staining. More than 95\% were strongly and homogeneously stained with CFSE, and unstained promastigotes were easily distinguished as previously described [12].

The cells were run on an analytical flow cytometer equipped with a laser emitting at $488 \mathrm{~nm}$ (FACSVantage, Becton \& Dickinson, San José, CA, USA). Whole cells were distinguished from fragments by gating based on the forward and side scatter signals. The receptor monocytes were detected by their fluorescence intensities relative to those of uninfected cells using the FL2 (red) and FL3 


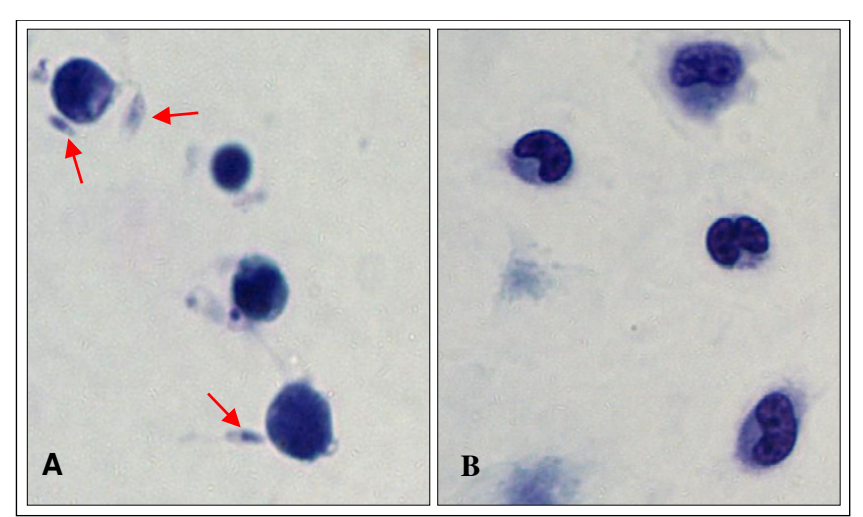

Figure I

The binding of Leishmania promastigotes to canine monocytes. (A) Promastigotes binding to peripherical monocytes from one animal naturally infected (ANI) with Leishmania chagasi in the presence of C5D serum. (arrows) (B) Only monocytes can be observed over coverslips (assay with absence of serum C5D). Giemsa. 1000x.

(brown) detectors. Both the frequency and the intensity of receptors associated with cells were determined. Analyses were performed on 30,000 gate events, and numerical data were processed using WinMDI software version 2.8 [15].

Figures 4(a) and 4(b) show the gate that was built to separate monocytes by size ( $\mathrm{x}$ axis) and granularity (y axis) from dogs naturally infected with $L$. chagasi. Figure 4C depicts CD11b-positive monocytes (72.61\%). Figures 4(d) and 4(e) show CD11b expression on monocytes 50 min after the start of the interaction with CFSE-stained $L$. chagasi in the presence and absence of C5D serum, respectively. The percentage of CD11b-positive monocytes decreased to $19.26 \%$ in the presence of serum; in the absence of serum it was $42.25 \%$. These data indicate that the expression of $\mathrm{CD} 11 \mathrm{~b}$ receptors decreased in the presence of serum because of the opsonized Leishmania promastigotes. The percentages of CSFE-Leishmania positive monocytes from serum-dependent and serum-independent cultures were $59.50 \%$ and $36,98 \%$, respectively. This means that the serum enhanced Leishmania binding to the monocytes (Figure 5).

\section{Canine peritoneal macrophages and monocyte-derived macrophages}

The numbers of peritoneal macrophages and monocytederived macrophages bound to Leishmania promastigotes were significantly increased when C5D serum was used during the interaction with the canine cells. Moreover, parasite survival, characterized by the presence of amastigote forms of Leishmania in macrophages, was also significantly increased in the presence of serum $(\mathrm{p}<0.01)$

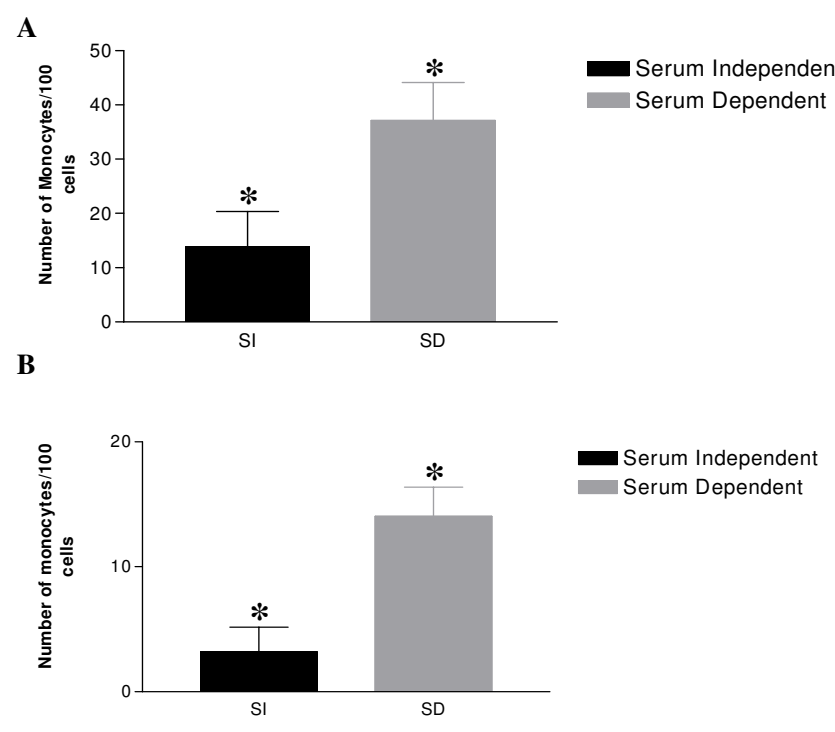

Figure 2

The binding of Leishmania promastigotes to canine monocytes. (A) Average of Leishmania promastigotes bound to monocytes of animals naturally infected (ANI) with L. chagasi in the presence or absence of C5D serum $(2.5 \times$ $10^{6}$ parasites/well) $(* p<0.01)$ (B) Average of Leishmania promastigotes bound to monocytes of animals experimentally infected $(\mathrm{AEI})$ with $L$. chagasi in the presence or absence of C5D serum $\left(2,5 \times 10^{6}\right.$ parasites/well) $\left(*_{p}<0.01\right)$.

(Figure 6). These results were found in both the naturally and the experimentally infected animals and were independent of incubation time ( $50 \mathrm{~min}$ or $48 \mathrm{~h}$ ) and parasite concentration (Figures 7,8$)(p<0.01)$. However, we observed no difference between the naturally and the experimentally infected dogs. As with the peripheral blood monocytes from naturally-infected dogs, significantly more cells were bound to Leishmania.

\section{Discussion}

There is an extensive literature on macrophage physiology and function in laboratory animals and humans. Several groups have reported characterizations of canine macrophage populations, including bone marrow-derived macrophages [5], peripheral blood monocytes [14,16] and canine macrophage cell lines derived from malignant histiocytosis [6]. However, few studies have concerned the isolation and culture of canine monocytes and monocytederived macrophages [17]. The procedures for obtaining these cells are not simple and are less convenient than obtaining cells from blood, although the number of monocytes that can be isolated from blood is usually relatively low [14]. Moreover, cultures of monocyte-derived macrophages are not easy to maintain in the laboratory. Bueno et al. (2005) [13] demonstrated a non-significant negative correlation between the number of monocyte- 
A

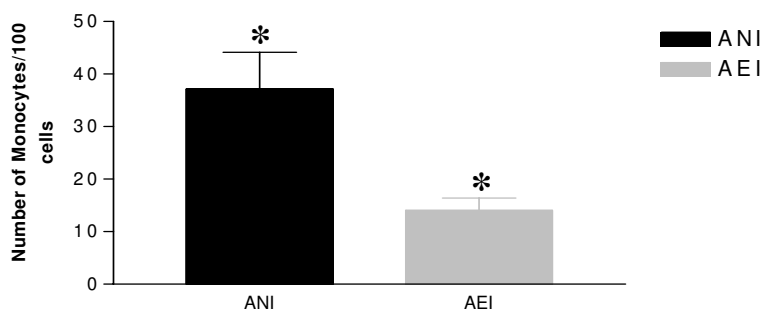

B

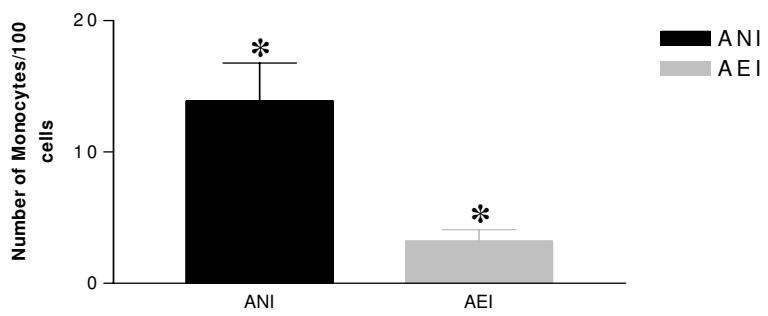

Figure 3

The binding of Leishmania promastigotes to canine monocytes. (A) to Leishmania promastigotes bound to monocytes from animals naturally infected (ANI) with $L$. chagasi and animals experimentally infected (AEI) with $L$. chagasi in the presence of C5D serum $\left(2.5 \times 10^{6}\right.$ parasites/well) $\left(^{*}\right) \mathrm{P}$ $<0.01$. (B) Leishmania promastigotes bound to monocytes from dogs naturally and experimental infected with $L$. chagasi in the absence of C5D serum $\left(2.5 \times 10^{6}\right.$ parasites/well) $\left(^{*}\right) \mathrm{P}$ $<0.01$.

derived macrophages after 10 days in culture and the number of monocytes in the original blood sample. These authors concluded that the number of monocytes in a given blood sample is not predictive of the macrophage yield after culture. However, flow cytometric analysis of the Teflon-adherent cells after ten days in culture revealed that monocyte-derived macrophages are phenotypically and functionally compatible with macrophages, and are larger and more granular than monocytes and lymphocytes.

In this work we have followed the method employed by Bueno et al (2005) [13], modified by supplementing the medium with GMCSF and autologous canine serum [18]. These modifications improved the survival of cell monolayers in vitro. Thus, we were able to obtain viable canine cell cultures with better morphology and sufficient numbers of cells for all the experiments. In addition, the canine cell cultures were maintained for a long time so that it was possible to carry out survival assays. Thus, on the basis of this culture standardization, we developed assays for comparing monocytes, monocyte-derived macrophages and peritoneal macrophages experimentally using the parasite Leishmania chagasi.
A

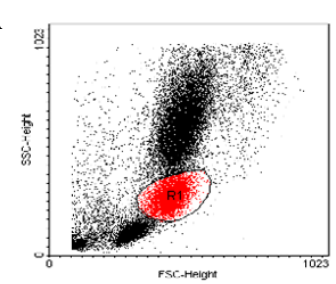

B

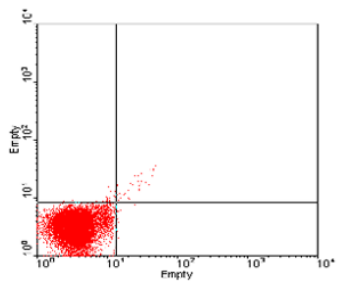

D

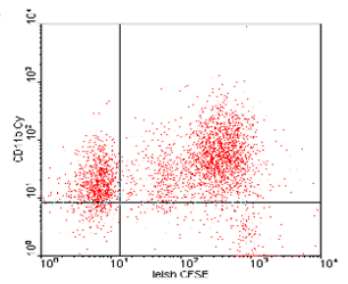

C

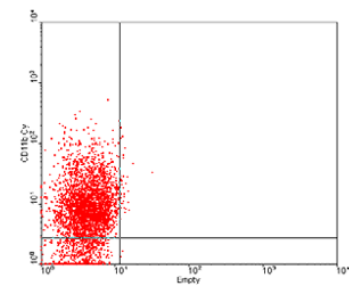

E

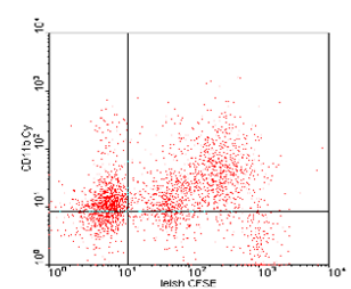

Figure 4

Flow cytometer analysis of CDI I b integrin expression and the binding of Leishmania promastigotes to canine monocytes. (A) Gate RI was built separating monocytes from animals naturally infected (ANI) with $L$. chagasi by cells size ( $x$ axis) and granularity ( $y$ axis). (B) Gate with mononuclear cells (control) (C) CDI Ib positive cells; (D) CDI Ib expression during the $L$. chagasi binding to mononuclear cells with the presence of C5D serum. (E) CDI Ib expression during the $L$. chagasi binding to mononuclear cells with the absence of C5D serum.

Our results are comparable to those obtained by other in vitro studies with monocytes/macrophages and $L$. major. Opsonized Leishmania promastigotes bind better to monocytes/macrophages in the presence of exogenous serum than they do in its absence $[19,20]$. Otherwise, this binding depends on the strict correspondence between the opsonized biological particles and the third complement receptor (CR3-CD11b/CD18) [9,18]. Our CD11b assays confirmed the importance of this receptor for the canine cell-L. chagasi system. Gonçalves et al. (2005) [12] previously described the importance of working with peritoneal macrophages from dogs naturally infected with $L$. chagasi. Now we have found similar results using peripheral monocytes.

We found an interesting result with peripheral blood monocytes and Leishmania promastigotes $50 \mathrm{~min}$ after the beginning of the interaction (binding assay): more promastigotes were bound to monocytes obtained from naturally-infected than from experimentally-infected dogs. 


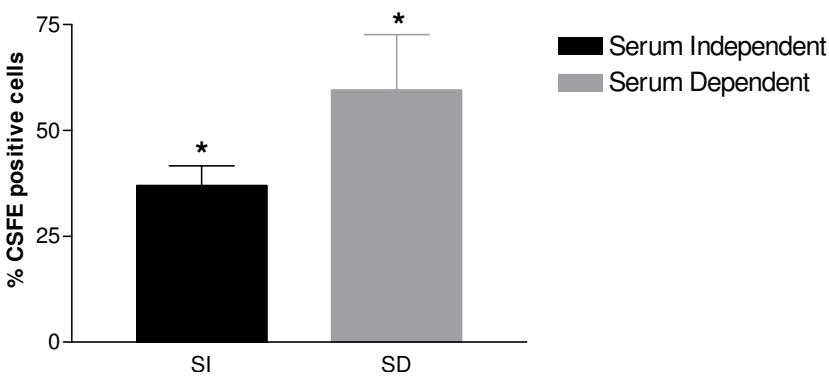

Figure 5

Flow cytometer analysis of the binding of Leishmania promastigotes to canine monocytes. Serum dependent conditions induce a higher association of Leishmania with monocytes as measured by both mean fluorescent intensity (CFSE) and percentage of monocytes associated with Leishmania. $(*) \mathrm{p}<0.05$.

These results could be consistent with the observation that amastigote forms of Leishmania are more easily found in tissues (for example, livers and spleens) from naturallyinfected than from experimentally-infected dogs (data not shown).

The experimental results regarding survival showed that promastigote forms of opsonized $L$. chagasi were more infective, because we found more promastigotes bound to the different cells. In consequence, after 48 h of binding, more amastigotes appeared inside the monocytes/macrophages. This is in accordance with Mosser \& Edelson (1985) [19], who used murine macrophages and L. major promastigotes. They showed that opsonized parasites are more infective, thereby improving the survival of amastigotes in macrophages. These findings will support continuing comparative studies involving canine monocytes, monocyte-derived macrophages and peritoneal macrophages. Since we have standardized the canine cell culture, we will be able to determine the phenotypic properties of these cells before and after L. chagasi infection using flow cytometry.

\section{Methods}

I - Animals

Animals naturally infected (ANI) with $\mathrm{L}$. chagasi

Five mongrel dogs of unknown age were obtained from the City of Santa Luzia (suburban area of Belo Horizonte, City Hall Zoonosis Department), MG, Brazil. All dogs were positive for Leishmania by indirect immunofluorescence (IIF), complement fixation tests (CFT) and ELISA (enzyme-linked immunosorbent assay). Animals were maintained with food and water "ad libitum". All animal studies were performed under the guidance and approval of the institute's animal welfare committee under the supervision of a certified veterinarian. The experimental

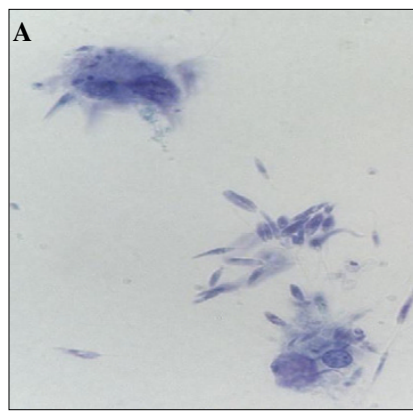

$\mathbf{B}$

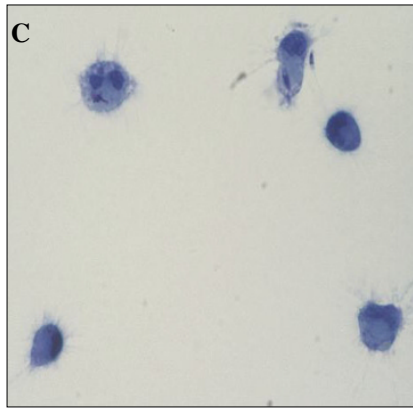

D
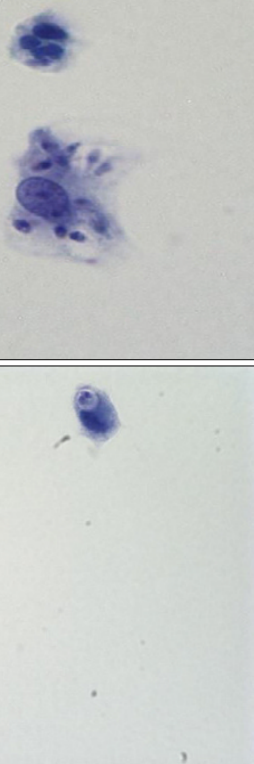

Figure 6

The binding and survival assays of Leishmania promastigotes to monocytes-derived macrophages. $(A)$ Promastigotas adhesion fifty minutes after incubation with the presence of C5D serum. (B) Note many amastigotes into could be seen 48 hours after interaction with the presence of C5D serum. (C) Promastigotas adhesion with the absence of serum. (D) Note some amastigotas could be seen 48 hours after interaction with the absence of C5D serum Giemsa. $1000 \times$.

protocol using dogs was approved by CETEA (Comitê de ética em experimentação animal - UFMG), number 034/ 2004.

Preparing parasites for canine experimental infection

Promastigote forms of Leishmania (Leishmania) chagasi strain MHOM/BR/1972/BH6 were maintained in hamsters and cultivated in vitro with NNN/MEM (Gibco - BRL - USA) with 10\% inactivated fetal calf serum (FCS) (Cultilab - SP - BR) supplemented with $2 \mathrm{mM}$ glutamine, 100 $\mathrm{UI} / \mathrm{ml}$ penicillin $\mathrm{G}$ and $100 \mu \mathrm{g} / \mathrm{ml}$ streptomycin, and maintained at $23^{\circ} \mathrm{C}$ in a FANEM ${ }^{\circledR}$ incubator (model 347). The Leishmania promastigotes in stationary phase were washed once with phosphate buffered saline (PBS), centrifuged at $200 \mathrm{~g}$ for $10 \mathrm{~min} / 18^{\circ} \mathrm{C}$ and resuspended to $1 \times$ $10^{7}$ parasites/ml in PBS.

\section{Experimental canine infection}

Experimental infection was carried out at HERTAPE CALIER SAÚDE ANIMAL S/A (Juatuba, MG). A group of 3-month-old laboratory-bred beagles (3 males and 2 females) were inoculated intravenously (saphenous vein) with $1 \times 10^{7}$ promastigotes $/ \mathrm{ml}$ resuspended in PBS. The 
A

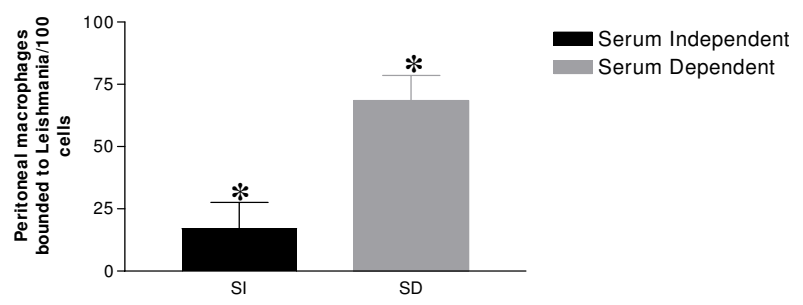

B

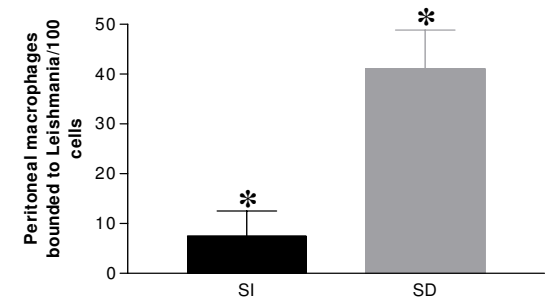

C

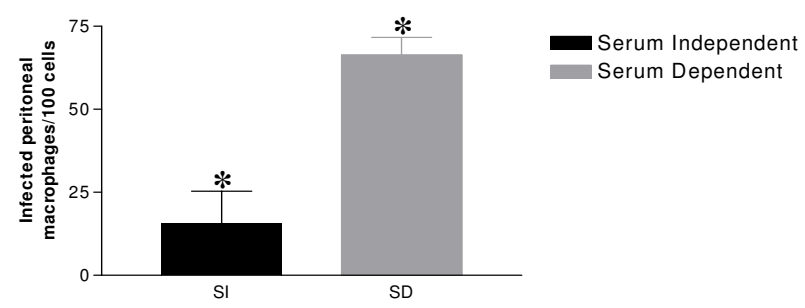

Figure 7

The binding and survival assays of Leishmania promastigotes to peritoneal macrophages. (A) Average of peritoneal macrophages binding to Leishmania from naturally infected animals with the presence or absence of C5D serum, after 50 min incubation (2,5 × $10^{6}$ parasites/well) (B) Average of peritoneal macrophages binding to Leishmania from experimental infected animals with the presence or absence of C5D serum, after 50 min incubation $\left(2,5 \times 10^{6}\right.$ parasites/well). (C) Average of infected peritoneal macrophages binding to Leishmania from naturally infected animals with the presence or absence of C5D serum after, fourth eight hour incubation $\left(5 \times 10^{6}\right.$ parasites/well) $\left(^{*}\right) p<0.0$ I.

infection was confirmed parasitologically and seroconversion was evident after 90 days post-infection. A second group of 5-month-old male L. chagasi seronegative beagles that served as uninfected controls were inoculated with sterile PBS at the time of L. chagasi inoculation of the experimentally infected animals (AEI).

\section{II - In vitro assays}

Obtaining canine monocytes and monocyte-derived macrophages Peripheral blood (120 ml) was collected from the external jugular vein into heparanized tubes. To isolate peripheral blood mononuclear cells (PBMC), the blood was centrifuged at $300 \mathrm{~g}$ for $10 \mathrm{~min}$ at room temperature. Plasma was separated and blood cells were resuspended in PBS
A

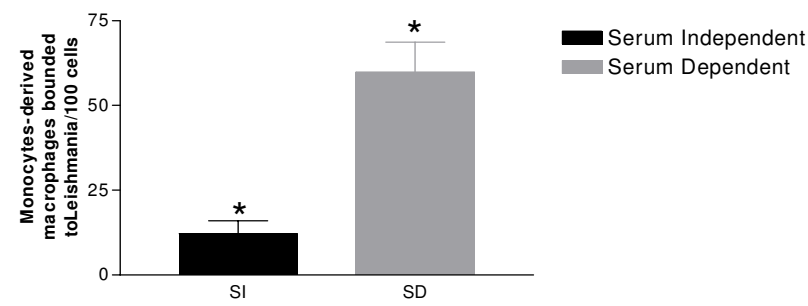

B

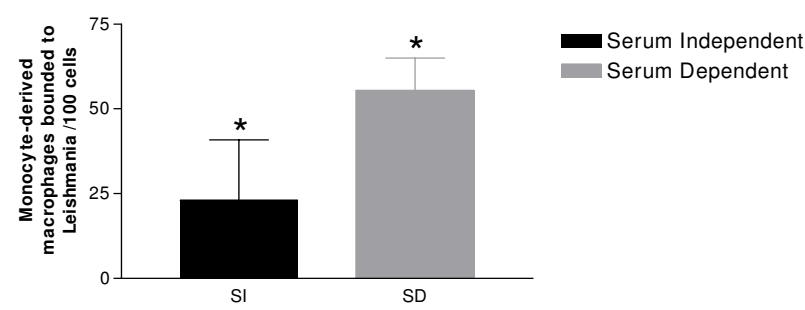

C

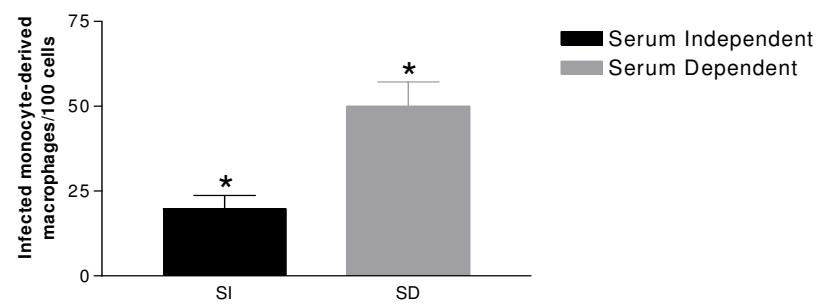

Figure 8

The binding and survival assays of Leishmania promastigotes to monocyte-derived macrophages. (A) Average of monocyte-derived macrophages binding to Leishmania from naturally infected animals with the presence or absence of C5D serum, after 50 min incubation $\left(5 \times 10^{6}\right.$ parasites/well) (B) Average of monocyte-derived macrophages binding to Leishmania from experimental infected animals with the presence or absence of C5D serum, after $50 \mathrm{~min}$ incubation ( $5 \times 10^{6}$ parasites/well). (C) Average of infected peritoneal macrophages binding to Leishmania from experimental infected animals with the presence or absence of C5D serum after, fourth eight hour incubation $\left(5 \times 10^{6}\right.$ parasites/well) $(*) \mathrm{p}<0.0 \mathrm{I}$.

(1:1 proportion), overlaid on Ficoll solution (HISTOPAQUE 1077 - SIGMA) at a ratio of 1 Ficoll:2 blood, and centrifuged at $200 \mathrm{~g}$ for $40 \mathrm{~min}$ at $4^{\circ} \mathrm{C}$. PBMC were separated, resuspended and washed twice in PBS (1:1 proportion), centrifuging at $300 \mathrm{~g}$ for $10 \mathrm{~min}$ at $4^{\circ} \mathrm{C}$. They were resuspended in $8 \mathrm{ml}$ RPMI-1640 (GIBCO, CARLSBAD, US) supplemented with 10\% FCS (CUTILAB), $200 \mathrm{mM} \mathrm{L-}$ glutamine, $10 \mathrm{mM}$ pyruvate, $10 \mathrm{mM}$ non-essential amino acids, $7.5 \% \mathrm{w} / \mathrm{v}$ sodium bicarbonate (Gibco, Carlsbad, USA), $50 \mathrm{IU} / \mathrm{ml}$ penicillin and $50 \mu \mathrm{l} / 100 \mathrm{ml}$ streptomycin. This medium was adjusted to $\mathrm{pH} 7.4$. 
In order to obtain monocyte-derived macrophages, another part of the peripheral blood suspension was transferred to Teflon flasks (NalgeNunc, Rochester, USA), supplemented with $10 \%$ autologous canine serum and 20\% DE GMCSF (granulocyte-macrophage colony-stimulating factor), and cultured at $37^{\circ} \mathrm{C}$ with $5 \% \mathrm{CO}_{2}$ (Forma Scientific Incubator, Waltham, USA). The medium was changed to remove non-adherent cells $24 \mathrm{~h}$ later and the culture was maintained under the same conditions for 10 days, changing the medium every 3 days. After 10 days in culture [21] the cells formed a monolayer, as observed by phase contrast microscopy. The macrophage-containing Teflon flasks were placed on ice for $30 \mathrm{~min}$ and agitated to harvest the cells. The cells were washed with cold PBS, as described by Bueno et al. (2005) [13] with modifications: we supplemented the medium with GMCSF obtained from L-cells (mouse fibroblasts) and autologous canine serum [18]. The cells were then were transferred to falcon tubes $(50 \mathrm{ml})$, centrifuged at $600 \mathrm{~g}$ for $15 \mathrm{~min}$ and resuspended in $1 \mathrm{ml}$ complete RPMI-1640. The concentration of the suspension was adjusted to $3 \times 10^{6}$ viable cells $/ \mathrm{ml}$ and counted in a Newbauwer chamber.

\section{Obtaining canine peritoneal macrophages}

To obtain the peritoneal macrophages, the dogs were anesthetized with $2.5 \%$ Thiopental sodium $(1 \mathrm{ml} / \mathrm{kg})$ and sacrificed using a lethal dose $(0.3 \mathrm{ml} / \mathrm{Kg})$ of $\mathrm{T}-61^{\oplus}$ (Intervet). The animals were positioned in decumbency and the peritoneal cavity was disinfected using iodinealcohol and washed with sterile saline, as described by Gonçalves et al. (2005) [12]. The washed peritoneal cell suspensions were adjusted to $3 \times 10^{6}$ cells $/ \mathrm{ml}$ in culture medium (D-10 - DMM + 10\% FCS + L-glutamine + penicillin-streptomycin).

Preparing parasites for assays for binding and survival in monocytemacrophages and peritoneal macrophages

Leishmania (Leishmania) chagasi parasites (stationary phase - MHOM/BR/1972/BH6) were adjusted to $5 \times 10^{7}$ cells/ml in "phagocytosis buffer" (PB) culture medium (equal parts of Dulbecco's Modified Eagle Medium and Medium 199 supplemented with 1\% BSA and $12.5 \mathrm{mM}$ HEPES) [18].

\section{Leishmania binding assays}

The interactions between Leishmania chagasi promastigotesand canine peritoneal monocytes, monocyte-derived macrophages and peritoneal macrophages were measured as follows. Cells were added to 24 -well plates containing $3 \times 10^{5}$ cells $/ 100 \mu \mathrm{l}$. All binding assays were performed in triplicate in a PB consisting of equal parts of medium 199 and Dulbecco's modified Eagle medium (Mediatech) supplemented with 1\% BSA [18]. Assays performed in the presence of serum were carried out at a concentration of
5\% of AKRJ C5-deficient mouse serum (C5D) [22] with a final volume of $400 \mu \mathrm{l}$ in each well.

The use of C5D serum obviates any problems associated with complement-mediated lysis of the parasites [1]. Promastigote forms of L. chagasi $\left(3 \times 10^{6}\right.$ or $5 \times 10^{6} /$ well $)$ were added to the monolayer cells. After $50 \mathrm{~min}$ incubation at $35^{\circ} \mathrm{C}$, unbound promastigotes were removed by thorough washing. The monolayers and bound promastigotes were fixed with $2.5 \%$ glutaraldehyde and stained with $10 \%$ Giemsa. The number of promastigotes bound per well was deduced using an optical microscope, assuming 100 monocytes-macrophages/well. All the experiments were done in triplicate [20].

\section{Survival assay}

Assays to measure the internalization of promastigotes into canine monocyte-derived macrophages and peritoneal macrophages and visualization of amastigotes were performed in a similar way to the binding assays after the Leishmania had interacted with the cells for $48 \mathrm{~h}$. The monolayers with intracytoplasmatic amastigotes in the macrophages were fixed with $2.5 \%$ glutaraldehyde and stained with $10 \%$ Giemsa. The number of parasitized macrophages and intracellular amastigotes was deduced by optical microscopy, assuming 100 macrophages/well. All experiments were done in triplicate [20].

\section{Staining of parasites and binding assay for flow Cytometric analysis} Promastigote forms of Leishmania were resuspended in 1 $\mathrm{ml}$ PBS $\left(5 \times 10^{7}\right.$ parasites $\left./ \mathrm{ml}\right)$ with $1 \mu \mathrm{l}$ of CFSE (carboxyfluorescein diacetate succinimidyl ester - Molecular Probes C-1157) from a $2.8 \mu \mathrm{g} / \mathrm{ml}$ stock in DMSO (dimethyl sulfoxide), and incubated in a $37^{\circ} \mathrm{C}$ water bath for 10 min in the dark as described by Gonçalves et al. (2005) [12]. The CFSE-stained Leishmania chagasi promastigotes were allowed to interact with canine cells as follows: (1) monocytes obtained from five dogs naturally infected with $L$. chagasi; (2) peritoneal macrophages from three naturally-infected dogs and one experimentally-infected dog. These interactions took place in polypropylene tubes to avoid cell adhesion. Canine cells $\left(100 \mu \mathrm{l}, 3 \times 10^{5}\right.$ cells $)$ and $100 \mu \mathrm{l}$ CFSE stained-Leishmania chagasi $\left(5 \times 10^{6}\right.$ cells) were combined in the tubes and maintained for 45-60 min at $37^{\circ} \mathrm{C}$ in a $5 \% \mathrm{CO}_{2}$ atmosphere. The assays were performed in the presence of either normal serum or a final concentration of 5\% C5-deficient mouse serum (from AKR/J mice) [22].

\section{Specific staining with anti-CR3}

Canine cells obtained as described above were stained with anti-CR3 (CD11b/CD18) rat anti-human CD18-RPE antibody (Serotec), which cross-reacts with canine cells. Nonconjugated, purified mouse anti-canine CD11b (Serotec) was conjugated using a Zenon tricolor kit 
(Molecular Probes - Z-25080), as described by the manufacturer, with the "C" compound that represents a $647 \mathrm{~nm}$ emission band and can be used with CFSE and R Phycoerythrin (RPE). The cells were incubated with labeled antibody solutions for $20 \mathrm{~min}$ at $4{ }^{\circ} \mathrm{C}$. After staining, the preparations were washed with $0.1 \%$ sodium azide in PBS, fixed with $200 \mu \mathrm{l} \%$ formaldehyde in PBS and kept at $4{ }^{\circ} \mathrm{C}$ until data were acquired by flow cytometry (FACSVantage, Becton \& Dickinson, San José, CA, USA).

\section{Binding analysis by flow cytometry}

The cells were run on an analytical flow cytometer equipped with a laser emitting at $488 \mathrm{~nm}$ (FACSVantage, Becton-Dickinson, San Diego, CA, USA). Whole cells were distinguished from fragments by gating based on the forward and side scatter signals. CFSE-stained promastigotes bound to macrophages were identified by their fluorescence intensities relative to those of uninfected cells using the FL1 (green) detector. Both the frequency of cells associated with promastigote forms of Leishmania and the intensity of cells associated with Leishmania were determined as described previously [12].

\section{Statistical analysis}

Results are given as a complete randomized design and the means from each group were compared using Student's t test; $p$ values less than 0.05 were considered significant. All analyses were carried out using Prism 3.0 software.

\section{Authors' contributions}

WMS; RRR, EPM, CFA, WLT: Carried out the necropsies

WMS, FCSA, EPM: Carried out the in vitro assays

MNM, CFA: Carried out all the Leishmania chagasi cultures

WMS, RRR: Carried out the statistical analysis

MSMM, RRR: Carried out the serological tests [CRF, ELISA, IFAT, TRALDd] for Leishmania infection

APSMF, WLT, WLT: Carried out the canine experimental infection with $L$. chagasi

WMS, WLT, WLT have made substantial contributions to conception and design, analysis and interpretation of data

\section{Acknowledgements}

We thank the Zoonosis Control Center of the municipality of Santa Luzia, (Belo Horizonte Metropolitan area), Minas Gerais, for the kind donation of the study animals. We thank for Hertape Calier fro providing the experimental animals. We also thank to Profa Leda Quércia Vieria and Alan Lane de Melo for gently providing the L-cells (mouse fibroblasts) and the C5 deficient mice (AKR/J), respectively - Laboratório Gnotobiologia e de taxonomia e biologia de invertebrados dos Departamentos de Imunologia e
Parasitologia da UFMG. This work was supported by Fundação de Amparo a Pesquisa do Estado de Minas Gerais (FAPEMIG Grant CDS2263/97; EDT$2124 / 03$ ) and Conselho Nacional de Desenvolvimento da Pesquisa Tecnológica e Científica - (grant CNPq 472287/0I-0-NV).

\section{References}

I. Mauricio IL, Stothard JR, Miles MA: The strange case of Leishmania chagasi. Parasitol Today 2000, 16(5): 188-189.

2. Deane LM, Deane MP: Visceral leishmaniasis in Brazil: geographical distribution and trnsmission. Rev Inst Med Trop Sao Paulo 1962, 4:198-2I2.

3. Pinelli E, Rutten VP, Bruysters M, Moore PF, Ruitenberg EJ: Compensation for decreased expression of $B 7$ molecules on Leishmania infantum-infected canine macrophages results in restoration of parasite-specific T-cell proliferation and gamma interferon production. Infect Immun 1999, 67(I):237-243.

4. Shaw SE, Anderson NV: Isolation and functional analysis of normal canine blood monocytes and resident alveolar macrophages. Am J Vet Res 1984, 45(I):87-90.

5. Tipold A, Zurbriggen A, Moore P, Schijns V, Jungi TW: Generation and functional characterisation of canine bone marrowderived macrophages. Res Vet Sci 1998, 64(2): | 25-132.

6. Pinelli E, Gebhard D, Mommaas AM, van Hoeij M, Langermans JA, Ruitenberg E], Rutten VP: Infection of a canine macrophage cell line with leishmania infantum: determination of nitric oxide production and anti-leishmanial activity. Vet Parasitol 2000, 92(3): $181-189$.

7. Mosser DM, Rosenthal LA: Leishmania-macrophage interactions: multiple receptors, multiple ligands and diverse cellular responses. Semin Cell Biol 1993, 4(5):315-322.

8. Brittingham A, Morrison CJ, McMaster WR, McGwire BS, Chang KP, Mosser DM: Role of the Leishmania surface protease gp63 in complement fixation, cell adhesion, and resistance to complement-mediated lysis. J Immunol I995, I 55(6):3 I02-3 I I I.

9. Kane MM, Mosser DM: Leishmania parasites and their ploys to disrupt macrophage activation. Curr Opin Hematol 2000, 7(1):26-3I.

10. Mosser DM, Handman E: Treatment of murine macrophages with interferon-gamma inhibits their ability to bind leishmania promastigotes. J Leukoc Biol I 992, 52(4):369-376.

II. Madeira M, Barbosa-Santos E, Marzochi M: Experimental infection of canine peritoneal macrophages with visceral and dermotropic Leishmania strains. Mem Inst Oswaldo Cruz 1999, 94(5):645-648.

12. Goncalves R, Vieira ER, Melo MN, Gollob KJ, Mosser DM, Tafuri WL: A sensitive flow cytometric methodology for studying the binding of $L$. chagasi to canine peritoneal macrophages. $B M C$ Infect Dis 2005, 5(I):39.

13. Bueno R, Mello MN, Menezes CA, Dutra WO, Santos RL: Phenotypic, functional, and quantitative characterization of canine peripheral blood monocyte-derived macrophages. Mem Inst Oswaldo Cruz 2005, 100(5):52I-524.

14. Ho CK, Babiuk LA: Long-term culture of canine peripheral blood monocytes in vitro. Can J Comp Med 1979, 43(2):223-228.

15. Trotter ]: 1996 [http://facs.scripps.edu/software.htlm\#winapps].

16. Reis AB, Teixeira-Carvalho A, Giunchetti RC, Guerra LL, Carvalho MG, Mayrink W, Genaro O, Correa-Oliveira R, Martins-Filho OA: Phenotypic features of circulating leucocytes as immunological markers for clinical status and bone marrow parasite density in dogs naturally infected by Leishmania chagasi. Clin Exp Immunol 2006, I 46(2):303-3II.

17. Rodrigues CA, Batista LF, Teixeira MC, Pereira AM, Santos PO, de Sa Oliveira GG, Freitas LA, Veras PS: Peripheral blood mononuclear cell supernatants from asymptomatic dogs immunized and experimentally challenged with Leishmania chagasi can stimulate canine macrophages to reduce infection in vitro. Vet Parasitol 2007, 143(3-4): 197-205.

18. Rosenthal LA, Sutterwala FS, Kehrli ME, Mosser DM: Leishmania major-human macrophage interactions: cooperation between Mac-I (CDIIb/CDI8) and complement receptor type I (CD35) in promastigote adhesion. Infect Immun 1996, 64(6):2206-2215. 
19. Mosser DM, Edelson PJ: The mouse macrophage receptor for C3bi (CR3) is a major mechanism in the phagocytosis of Leishmania promastigotes. J Immunol I985, I35(4):2785-2789.

20. Mosser DM, Edelson PJ: The third component of complement (C3) is responsible for the intracellular survival of Leishmania major. Nature 1987, 327(6 I 20):329-33।.

21. Wardley RC, Lawman MJ, Hamilton F: The establishment of continuous macrophage cell lines from peripheal blood monocytes. Immunology 1980, 39(1):67-73.

22. Cinader B, Dubiski S, Wardlaw AC: Distribution, Inheritance, and Properties of an Antigen, MubI, and Its Relation to Hemolytic Complement. J Exp Med 1964, I 20:897-924.

Publish with Bio Med Central and every scientist can read your work free of charge

"BioMed Central will be the most significant development for disseminating the results of biomedical research in our lifetime. "

Sir Paul Nurse, Cancer Research UK

Your research papers will be:

- available free of charge to the entire biomedical community

- peer reviewed and published immediately upon acceptance

- cited in PubMed and archived on PubMed Central

- yours - you keep the copyright

Submit your manuscript here:

http://www.biomedcentral.com/info/publishing_adv.asp 